\title{
Impact of water saturation and cation concentrations on wettability alteration and oil recovery of carbonate rocks using low-salinity water
}

\author{
Mohammad Reza Zaeri ${ }^{1} \cdot$ Hamidreza Shahverdi $^{1} \cdot$ Rohallah Hashemi $^{1} \cdot$ Mohsen Mohammadi $^{1}$
}

Received: 4 August 2018 / Accepted: 10 September 2018 / Published online: 22 September 2018

(c) The Author(s) 2018

\begin{abstract}
In this study, the effect of initial water saturation on the oil recovery for carbonate rocks is investigated using spontaneous imbibition experiments. The experiments are performed using 20 times diluted sea water as imbibing fluid and the sea water as initial water. In addition, the impact of $\mathrm{pH}$ and $\mathrm{Ca}^{2+}, \mathrm{Mg}^{2+}, \mathrm{Na}^{+}$, and $\mathrm{K}^{+}$cations concentration change of imbibing fluid are investigated during tests. These results help to identify the active cations in the wettability alteration process of carbonate rocks during the low-salinity water injection. A mechanism is proposed to describe the effect of initial water saturation on the oil recovery by low-salinity water injection. The impact of initial water saturation on the wettability alteration might be positive or negative depending on its value and the rock permeability. The comparison of divalent cations concentrations shows that the minimum adsorption of $\mathrm{Ca}^{2+}$ and maximum desorption of $\mathrm{Mg}^{2+}$ lead to maximum oil recovery of spontaneous imbibition. The results confirm that three cations of $\mathrm{Ca}^{2+}, \mathrm{Mg}^{2+}$, and $\mathrm{Na}^{+}$are active for wettability alteration of carbonate rocks in the presence of sea water as initial water and diluted sea as imbibing fluid, whilst the amounts of potassium remain constant.
\end{abstract}

Keywords EOR $\cdot$ Low-salinity water injection $\cdot$ Carbonate rocks $\cdot$ Spontaneous imbibition $\cdot$ Water saturation $\cdot$ Cation exchange

\section{Introduction}

The development of technology in the recent century has increased the consumption of the fossil fuels in the world, since the oil production from many reservoirs have been declined, the oil companies are interested to invest for the technologies that enhance the oil recovery (EOR technology). Performance of the EOR techniques significantly depends on the reservoir rock and fluids properties. Some of the reservoir rocks are naturally fractured and, therefore, the flow mechanisms in these reservoirs are different from nonfractured reservoirs. The rock type of the fractured reservoirs is mainly carbonate, whereas the non-fractured reservoirs are generally sandstone. The fractured carbonate reservoirs consist of two media including fracture and matrix. The residual oil in the fractured reservoirs is mainly trapped in the matrix region due to low permeability and high capillarity effect

Hamidreza Shahverdi

hr_shahverdi@cc.iut.ac.ir

1 Department of Chemical Engineering, Isfahan University of Technology, Isfahan 84156-83111, Iran
(Hognesen et al. 2005). In general, the matrices have low permeability (less than $1 \mathrm{mD}$ to $100 \mathrm{mD}$ ), and consequently, the capillary forces are dominant in the matrix region of carbonate rocks, so that the oil recovery from these rocks is lower than the sandstone reservoirs.

Changing the rock and fluid properties (i.e., viscosity, interfacial tension, relative permeability, wettability, and capillary forces) to the favorable conditions are the main ideas behind the EOR methods to displace the trapped oil toward production wells in the reservoir (Green and Willhite 1998b). Among the various mechanisms, the wettability alteration of the rock from the oil-wet to the water-wet is one of the most favorable mechanisms in the case of carbonates. In this mechanism, the capillary pressure is changed, especially in the matrix region of the carbonate fractured reservoirs, so that the water is imbibed into the matrix and displaces the trapped oil (Morrow and Mason 2001).

The chemical EOR methods are those that add chemical agents to the injection fluid (e.g., surfactant, polymer, foam flooding, and nano) or tune the composition of injection brine (low salinity and smart water injection) to change the rock and fluid properties towards favorable conditions. 
In the polymer injection, a water-soluble polymer is added to the water, such that the viscosity of water increased, and hence, the mobility ratio is improved (Needham and Doe 1987). The surfactants' flooding changes the interfacial tension between oil and injection fluid, such that the capillary forces decrease and the trapped oil is release from the tight pores (Green and Willhite 1998a). The Nano EOR as a recent approach is performed by dispersing a nano particle (e.g., silica) in the injection fluid to change the rock-fluid surface properties (wettability or IFT). One of the main challenges in Nano EOR is stability of nanoparticles in the carrier fluid (brine) which may affect the performance of this method (Karimi et al. 2012).

Many studies have shown that lowering the total salinity of injected water can significantly improve the oil recovery (McGuire et al. 2005a; Tang and Morrow 1997b). This method is called as low-salinity water injection. Some other studies have depicted that changing the ionic composition of injected fluid can affect the oil recovery and this technique is referred as smart water injection (Morrow et al. 1998).

The wettability alteration may occur via various EOR methods such as smart water injection (Gandomkar and Rahimpour 2015; Rivet et al. 2010), low-salinity water injection (Tang and Morrow 1997a; Shehata and Nasr El-Din 2015; Samira et al. 2018), and Nano EOR (Hendraningrat et al. 2013). There exist some conventional experimental methods to investigate the occurrence and contribution of wettability alteration during various EOR techniques such as contact angle measurement (Mahani et al. 2015a), flotation test (Anderson 1986), adhesion test (Anderson 1986; Tiab and Donaldson 2004), spontaneous imbibition (Shehata and Nasr El-Din 2015), core-flooding (Wickramathilaka et al. 2011), and capillary pressure measurement (Anderson 1986; Shaker Shiran and Skauge 2012).

Spontaneous imbibition test acceptably simulates the production from fractured reservoirs in the tertiary oil recovery stage. In this type of experiment, the fluid in the fracture (brine around the core) penetrates into the core plug and drives the trapped oil out of the core. The fluid displacement in the Spontaneous imbibition phenomena is governed by both capillary and gravity forces. However, the small height of core plug and also the significance of capillary pressure in the case of tight rocks might lead to the capillary force as dominant mechanism, whereas the gravity force becomes negligible. Wettability alteration of pore surfaces towards water-wetness by imbibing fluid would be one of the main mechanisms that lead to the oil production from core plug during imbibition test. As above mentioned, the low-salinity water injection has been proposed to reach this purpose (Tang and Morrow 1997a; Shehata and Nasr El-Din 2015).

The followings are some of the factors affecting the performance of low-salinity water injection which are drawn from the experimental studies available in the literature:
- The oil recovery has been improved by increasing of the $\mathrm{PH}$ which is attributed to the reduction of the interfacial tension between water and oil, and emulsification of the oil in the brine (Tang and Morrow 1999; McGuire et al. 2005b).

- The composition of oil (polar, acidic, and basic component) influences the oil production by low-salinity water injection. The low-salinity water injection is more efficient for the crude oils that contain higher acidic and polar components (Hadia et al. 2012; Shaddel and Tabatabae-Nejad 2015).

- The amount of connate water saturation in the rock can change the oil recovery during low-salinity flooding which causes recovery factor enhancement in the case of sandstone samples (Zhang and Morrow 2006; Viksund et al. 1998).

- The clay particles in the rock are an effective parameter on the performance of the low-salinity water injection (Wickramathilaka et al. 2011). However, the previous studies have indicated the LSE on the carbonate cores which are free of clay Zaeri et al. (2018). Therefore, the presence of clay material would enhance the ultimate oil recovery; however, it is not compulsory in the case of carbonate rocks.

- The performance of low-salinity injection is affected by the initial status of rock wettability (Al-Attar 2010; Salathiel 1973). Shaker Shiran et al. (2013) concluded that the initial intermediate wettability made a better response to low salinity towards water-wet state (Shaker Shiran and Skauge 2013).

- The temperature is an effective parameter on the rock and fluid properties. For instance, it can affect the viscosity, fluid expansion, mineral dissolution, and wettability. The previous works have depicted positive effect of temperature on the oil recovery during spontaneous imbibition test (Shehata and Nasr El-Din 2015; Zhang et al. 2007; Schembre et al. 2006; Tang and Morrow 1997a; Zaeri et al. 2018).

- The type of ions (and charges of them) in the injected brine and resident brine have a significant impact on the oil recovery during low-salinity water injection. One of the important ions is sulfate $\left(\mathrm{SO}_{4}{ }^{2-}\right)$ that positively effects the low-salinity performance (Hognesen et al. 2005; Zhang and Austad 2006). Shehata et al. (2015) concluded that existence of divalent ions in the connate water is the more effective compared to monovalent in the sandstones cores (Shehata and Nasr El-Din 2015). In addition, the effects of cations have studied in some studies (Rashid et al. 2015; Al-Attar et al. 2013; Romanuka et al. 2012; Austad et al. 2011).

As above mentioned, one of the important factors which has recognized to be effective in the performance 
of low-salinity water injection is the connate water saturation. Wichramathilak et al. (2011) performed spontaneous imbibition tests using sandstone rocks with different permeabilities. The 15 times diluted sea water as imbibition fluid was used in their work. They concluded that the cores with lower permeability-containing the higher connate water saturation resulted in higher oil recovery compared to the higher permeability rock sample-containing lower $S_{\mathrm{wc}}$. This study confirmed the positive impact of $S_{\mathrm{wc}}$ on the oil recovery from sandstone rocks (Wickramathilaka et al. 2011). Zhou et al. (2000) characterized the impact of initial water saturation using water flooding and spontaneous imbibition experiments on the Berea Sandstone cores. The results showed that the initial water saturation in a certain range (15-25\%) positively affected the wettability towards the water-wet condition, whereas the oil recovery from water-flooding tests decreased with increase in water-wetness of the rock (Zhou et al. 2000). On the other hand, Viksund et al. (1998) carried out some spontaneous imbibition tests on the sandstone and chalk samples. The results showed that the imbibition rate for the samples decreases with increasing initial water saturation, whereas, in the chalk cores, the trend was vice versa, until a certain value of initial water saturation. The observed contrast in the effect of initial water saturation on the imbibition rate was explained based on the change in relative permeability and capillary pressure curves (Viksund et al. 1998). The effect of initial water saturation in the imbibition test was examined on the oil recovery from chalk by Puntervold et al. (2007). Their results showed that the variation of the initial water saturation from 10 to $22 \%$ had no effect on the oil recovery (Puntervold et al. 2007). It can be concluded that no general agreement exists on the effect of initial water saturation in the oil recovery of imbibition experiments using low-salinity water injection, especially in the case of carbonate rocks.

On the other hand, the ion exchange between rock surface and brine has been proposed as an important mechanism which leads to wettability alteration towards water-wetness (Shaddel et al. 2014; Alagic and Skauge 2010; Nasralla et al. 2011; Shehata and Nasr El-Din 2015; Zaeri et al. 2018). fine migration (Tang and Morrow 1999), $\mathrm{pH}$ increase (McGuire et al. 2005b), salting in (RezaeiDoust et al. 2009), double layer expansion (Ligthelm et al. 2009), chemical reaction (Austad et al. 2010), mineral dissolution, and surface charge change (Mahani et al. 2015b) are the other famous mechanisms. The majority of these mechanisms suggest that the concentration of ions should change in the imbibing fluid during imbibition test to wettability alteration that takes place. According to the ion-exchange mechanism, rock surface and resident brine are at the ionic equilibrium, while the salinity of injected brine changes, the balance condition of the rock charges alters, and hence, the ion exchange between brine and rock surface occurs to reach the new equilibrium state. The ion-exchange causes the rock wettability alteration towards water-wetness by detachment of the carboxyl group (in the oil) from the rock surface (Lager et al. 2008). The effect of various ions has been studied on the wettability alteration in the presence of low-salinity water injection.

Alattar et al. (2013) conducted the low-salinity waterflooding test as well as IFT and contact angle measurement on the carbonate sample using sea water. The results depicted that reduction of brine salinity from 200,000 to $5000 \mathrm{ppm}$ improved oil recovery about $20 \%$. The increasing of calcium $\left(\mathrm{Ca}^{2+}\right)$ in the injected brine yielded to decrease in oil production, whereas the impact of sulfate $\left(\mathrm{SO}_{4}{ }^{2-}\right)$ was positive on the wettability alteration and oil recovery (Al-Attar et al. 2013). Rashid et al. (2015) carried out spontaneous imbibition tests and contact angle measurements on the carbonate rocks using smart water to identify the impact of monovalent and divalent ions on the wettability alteration. The results indicated that $\mathrm{Mg}^{2+}$, $\mathrm{Ca}^{2+}$, and $\mathrm{SO}_{4}{ }^{2-}$ play a major role in wettability alteration, whereas neither $\mathrm{Na}^{+}$nor $\mathrm{Cl}^{-}$is able to change the wettability of carbonate rocks (Rashid et al. 2015). Austad et al. (2011) investigated the impact of low-salinity water injection on the chalk and limestone samples. They concluded that the tertiary low-salinity injection was efficient for the carbonate (limestone) samples contained the anhydrite $\left(\mathrm{CaSO}_{4}\right)$, while LSE was not observed in the chalk core that are free of anhydrite (Austad et al. 2011). Zahid et al. (2012) carried out low-salinity water injection on the carbonate reservoir rocks and outcrop chalk samples using diluted sea water at various temperatures. The LSE was not detected on the carbonate cores at ambient temperature, but a significant oil recovery was achieved on the carbonate cores at the elevated temperature $(90 \mathrm{C})$. The recovery from outcrop chalk cores was not affected by low-salinity water, both at ambient and reservoir temperature (Zahid et al. 2012). Most of these works indicated that the ion concentration should be changed during low-salinity water injection to wettability alteration that occurs (Shehata and Nasr El-Din 2015; Rivet et al. 2010; Gandomkar and Rahimpour 2015); however, various mechanisms have been proposed for this phenomenon (as mentioned above) (Tang and Morrow 1999; McGuire et al. 2005b; RezaeiDoust et al. 2009; Ligthelm et al. 2009; Austad et al. 2010; Mahani et al. 2015b; Lager et al. 2008). In addition, if the low-salinity water injection method is performed as a tertiary oil recovery method, at least a portion of saturated water is diluted as a result of secondary water injection. Since the sea water is usually injected for pressure maintenance, the ions' concentration of the saturated water might approach to sea water. Consequently, the ion concentration change and wettability alteration in the low-salinity water injection should be investigated using sea water as initial water

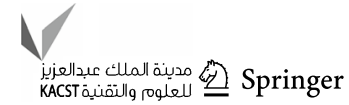


saturation; moreover, the effect of the amounts of initial water saturation on recovery factor should be studied in this ion concentration. To investigate this, Zaeri et al. (our previous work) performed some spontaneous imbibition experiments in carbonate rocks using various amounts of dilution of sea water as imbibition fluid and sea water as connate water. They optimized the dilution of sea water for maximum oil recovery in low-salinity sea water imbibition. The results indicated that the 20 times diluted sea water could recover more oil in comparison with the other studied concentrations (Zaeri et al. 2018).

As already mentioned, the effect of initial water saturation and also the ion concentration change during lowsalinity water injection in carbonate rocks are still questionable and need more study. In this study, the effect of initial water saturation in the spontaneous imbibition was investigated using 20 times diluted sea water as imbibing fluid and sea water as the initial water. The experiments performed using reservoir and outcrop carbonate rocks (mostly limestone) with very low permeability taken from southwest of Iran. The results are compared and discussed, so that a mechanism was proposed for the effect of initial water saturation on the oil recovery by low-salinity water injection. In addition, the cation concentrations and $\mathrm{pH}$ of imbibing fluids were measured before and after experiments; subsequently, the measured values were compared and discussed.

This should be pointed out that this study is along the research was conducted in the petroleum center at Isfahan University of Technology (IUT) an part of it was published previously (McGuire et al. 2005a). Hence, the results of this paper are compared against our other publication (with same core and oil) (McGuire et al. 2005a).

\section{Experimental methods, material, and instruments}

\section{Rock sample}

The rock samples used in this study were carbonate taken from an actual reservoir located in the south of Iran. The ranges of absolute permeability of the rock samples are between 0.4 and $3 \mathrm{mD}$, and porosity between $15-18 \%$. Three outcrop cores, two carbonates and the other sandstone, are also used for the comparison with the actual reservoir cores. The physical properties of the cores are given in Table 1 . The X-ray diffraction (XRD) analysis of the carbonate reservoir samples is demonstrated in Table 2. As can be observed, the rock is mainly composed of calcite $\left(\mathrm{CaCO}_{3}\right)$ and small amount of dolomite. The XRD results show that the carbonate cores are free of any clay content, because the percentage of kaolinite (main clay mineral) is zero.

\section{Crude oil}

The crude oil used in this research was sampled from a carbonate reservoir located in the south of Iran. The oil has a relatively low asphaltene content and low acid number (TAN). The physical properties of the oil are given in Table 3. The previous studies have pointed out that the asphaltene content of the oil has a significant impact on the original wettability of the rock (Tang and Morrow 1997a; Hadia et al. 2012). In addition, the presence of acidic component(s) in oil (quantified by acid number) can influence the wettability alteration process and, consequently, oil recovery by the low-salinity injection (Shaddel and Tabatabae-Nejad 2015).

Table 1 Physical properties of the rock samples

\begin{tabular}{llllrrr}
\hline Core I.D. & Rock type & Diameter $(\mathrm{cm})$ & Length $(\mathrm{cm})$ & Pore volume $(\mathrm{cc})$ & Porosity $(\%)$ & Permeability $(\mathrm{mD})$ \\
\hline 1 & Reservoir carbonate & 3.80 & 4.90 & 10.84 & 19.50 & 2.46 \\
2 & Reservoir carbonate & 3.80 & 4.59 & 8.98 & 17.25 & 0.40 \\
3 & Reservoir carbonate & 3.80 & 4.98 & 10.81 & 19.14 & 3.04 \\
4 & Outcrop carbonate & 3.80 & 4.86 & 9.83 & 17.84 & 182.25 \\
5 & Outcrop carbonate & 3.77 & 6.06 & 11.57 & 17.10 & 185.43 \\
6 & Outcrop sandstone & 3.80 & 5.71 & 5.44 & 8.40 & 20.53 \\
\hline
\end{tabular}

Table 2 XRD analysis of the carbonate reservoir samples

\begin{tabular}{lllllll}
\hline Mineral & Calcite & Dolomite & Gypsum & Pyrite & Quartz & Kaolinite \\
\hline$\%$ Mass & $94 \%$ & $6 \%$ & 0 & 0 & 0 & 0 \\
\hline
\end{tabular}


Table 3 Oil and brine properties at $20{ }^{\circ} \mathrm{C}$

\begin{tabular}{llll}
\hline Property & Crude oil & Brine & Standard method \\
\hline Density, gr/cc & 0.861 & 1.015 & ASTM D-1298 \\
Viscosity, cP & 8.540 & 0.986 & ASTM D 445 \\
Total acid number (TAN), mg KOH/g oil & 0.100 & - & UOP 565 \\
Asphaltene content, \% g/g oil & 0.400 & - & IP 143 \\
Interfacial tension (oil/brine), dynes/cm & 40.430 & & \\
\hline
\end{tabular}

Table 4 Composition of connate and imbibing brine

\begin{tabular}{lll}
\hline Type of ion & $\begin{array}{l}\text { Concentration of connate } \\
\text { water (PPM) }\end{array}$ & $\begin{array}{l}\text { Concentration of } \\
\text { imbibing fluid } \\
(\mathrm{PPM})\end{array}$ \\
\hline $\mathrm{Na}^{+}$ & 27,000 & 1350 \\
$\mathrm{~K}^{+}$ & 445 & 22.25 \\
$\mathrm{Ca}^{2+}$ & 510 & 25.5 \\
$\mathrm{Mg}^{2+}$ & 1305 & 65.25 \\
$\mathrm{Cl}^{-}$ & 47,152 & 2357.6 \\
$\mathrm{SO}_{4}{ }^{2-}$ & 6220 & 311 \\
$\mathrm{HCO}_{3}{ }^{-}$ & 330 & 16.5 \\
$\mathrm{TDS}^{-}$ & 82,962 & 4148.1 \\
Ionic strength (mol- & 1.522 & 0.0761 \\
ar e & & \\
\hline
\end{tabular}

\section{Brine}

The sea water (sampled from the Persian-Gulf) and diluted sea water were used as connate water and imbibing fluid, respectively. The physical properties of the sea water are presented in Table 3 . Table 4 presents the ions concentration of the sea water and connate water. As can be seen, the total dissolved solid (TDS) of diluted sea water and connate water is about 4000 and $83,000 \mathrm{ppm}$.

\section{Core preparation}

First, the core samples were cleaned in the Soxhlet apparatus using methanol and toluene as the solvents. Then, the cores were dried in the oven at $110{ }^{\circ} \mathrm{C}$ for $12 \mathrm{~h}$. The dimensions and weight of the core were measured, and then, the cores were saturated by the brine using evacuation system. To be sure about the complete saturation of the cores with the brine, they were flooded in the core-flooding apparatus (Fig. 1). Having established the steady-state flow rate in the core, the absolute permeability of the core was calculated using Darcy law (Amyx et al. 1988). The porosity of each core was calculated by comparing the weight of dry and saturated core. The connate water in the rock was established by flooding the core by the crude oil. The flooding was performed to the point that no brine was observed in the outlet and it was continued with the oil volume of four times of core pore volume. Then, the core samples were

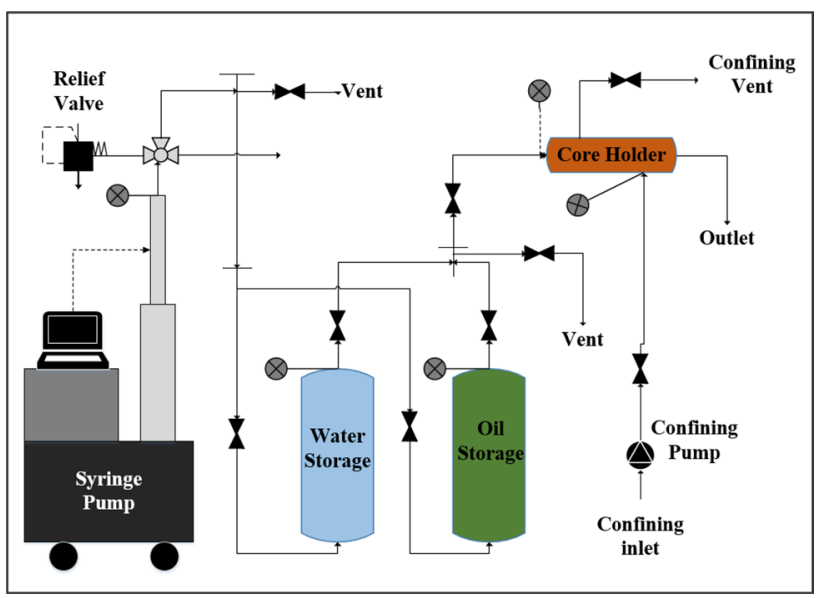

Fig. 1 Schematic of core-flooding apparatus (McGuire et al. 2005a)

aged in the oven at $75{ }^{\circ} \mathrm{C}$ for 2 weeks (the aged time was measured and optimized using contact angle measurement) to achieve the mixed-wet wettability condition, so that the pores occupied by the connate water remain water-wet, while the oil-saturated pores become oil-wet.

\section{Spontaneous imbibition test}

The Amott-cell apparatus was used to perform the spontaneous imbibition tests at atmospheric pressure and temperature of $75^{\circ} \mathrm{C}$. The list of these experiments is presented in Table 5. In our previous study, experiments were performed to obtain the optimum salinity of brine. The results showed that the 20 times diluted sea water recovered the maximum amount of oil in the imbibition tests (Zaeri et al. 2018); consequently, in this study, the 20 times diluted sea water is used to investigate the impact of initial water saturation and rock type at the optimum salinity of injected brine and adsorption-desorption of cations.

\section{$\mathrm{PH}$ and ion concentration measurement}

To investigate the contribution of $\mathrm{pH}$ change and ionexchange mechanisms in the presence of sea water and carbonate rocks (mainly limestone), the $\mathrm{pH}$ and cation concentrations of imbibing fluid were measured before and after each test. A Metrohm $744 \mathrm{pH}$ meter, with precision of 0.01 ,

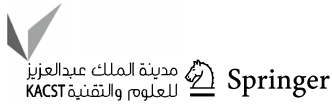


Table 5 List of spontaneous imbibition experiments at various core and fluid conditions

\begin{tabular}{|c|c|c|c|c|c|c|c|}
\hline Test I.D. & Core I.D. & Rock type & $\begin{array}{l}\text { Test tem- } \\
\text { perature } \\
\left({ }^{\circ} \mathrm{C}\right)\end{array}$ & $\begin{array}{l}\text { Times dilution of } \\
\text { imbibing fluid }\left(\operatorname{tdsw}^{\mathrm{a}}\right)\end{array}$ & Connate water & $\begin{array}{l}\text { Amount of con- } \\
\text { nate water (\%P.V.) }\end{array}$ & References \\
\hline 1 & 3 & Carbonate & 75 & 20 & None & 0.0 & Zaeri et al. (2018) \\
\hline 2 & 1 & Carbonate & 75 & 20 & Sea Water & 9.10 & This work \\
\hline 3 & 2 & Carbonate & 75 & 20 & Sea Water & 25.71 & This work \\
\hline 4 & 3 & Carbonate & 75 & 20 & Sea Water & 33.21 & This work \\
\hline 5 & 5 & Carbonate (outcrop) & 75 & 20 & Sea Water & 25.00 & This work \\
\hline 6 & 4 & Carbonate (outcrop) & 75 & 10 & None & 0.0 & Zaeri et al. (2018) \\
\hline 7 & 6 & Sandstone & 75 & 20 & None & 0.0 & This work \\
\hline 8 & 1 & Carbonate & 75 & 10 & None & 0.0 & Zaeri et al. (2018) \\
\hline
\end{tabular}

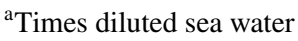

manufactured in Switzerland, was used to measure the $\mathrm{pH}$. In addition, the cation concentrations were determined using atomic absorption spectroscopy (Buck Scientific 210-VGP made in USA).

\section{Results and discussion}

\section{Oil recovery profile}

In the spontaneous imbibition process, the fluid in the fracture (brine around the core) penetrates into the rock and pushes the resident fluid (oil) out of the core. This process is due to the positive capillary pressure between wetting and non-wetting fluids in the porous media (the wetting phase pressure is lower than the non-wetting phase pressure). When all the faces of the core are open to the brine both co-current and counter-current flow may occur. The fluid displacement in the spontaneous imbibition phenomena is governed by the both capillary and gravity forces.

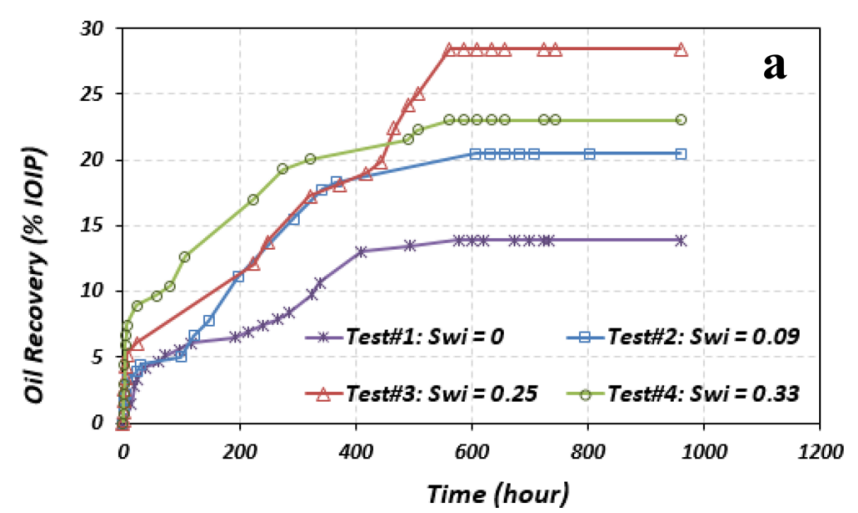

Fig. 2 Oil recovery (\% IOIP) versus time resulted from spontaneous imbibition tests using carbonate cores (low permeable $\sim 0.5-3 \mathrm{mD}$ ) having various initial water saturations. Left picture (a) is presented
However, for the case in which the height of rock is small enough and also the capillary pressure is significant (tight rock), the dominant mechanism is capillary force, whereas the gravity force becomes negligible. In the case of mixedwet rock, the brine cannot diffuse into the rock at the start of test, because the brine is non-wetting phase against oil in the pores (capillary pressure is negative). However, the ion exchange between brine and rock surface alters the wettability of the outer pores towards the water-wet, and thus, the brine imbibes into the rock and displaces oil. The interaction between brine and rock surface is gradually developed to the internal pores, and hence, the wettability of other parts of rock changes toward water-wetness.

Figure 2a demonstrates the oil recovery [as percentage of initial oil in-place (IOIP)] versus time resulted from spontaneous imbibition tests using brine with salinity of 20 times diluted sea water and carbonate rocks having different initial water saturations. As can be observed from this figure, the test with $25 \%$ of the initial water saturation gives higher ultimate oil recovery compared to the other ones. To make more

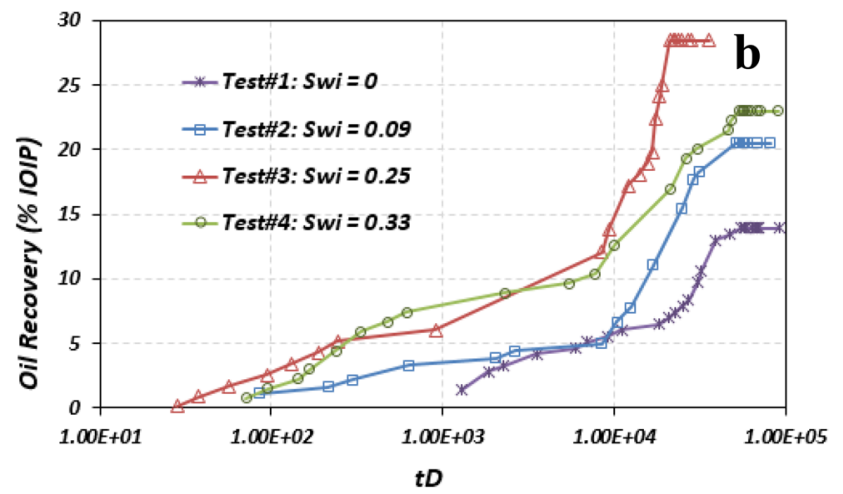

against time and right picture (b) is plotted versus dimensionless time (tD) in logarithmic scale 
reasonable comparison between various recovery curves, the oil production versus dimensionless time $\left(t_{\mathrm{D}}\right)$ in the logarithmic scale is presented in Fig. 2b. The dimensionless time used in this study calculated as follows:

$t_{\mathrm{D}}=\sqrt{\frac{K}{\phi}} \frac{\sigma}{L_{\mathrm{c}}^{2} \sqrt{\mu_{w} \mu_{o}}} t$

This equation was suggested by Ma et al. (1997), where $K$ is the permeability, $\phi$ the porosity, $\sigma$ the interfacial tension between oil and brine, $\mu$ the viscosity, $t$ the time, and $L_{\mathrm{c}}$ is the characteristic length defined by the following:

$$
L_{c}=\sqrt{\frac{V_{b}}{\sum_{i=1}^{n} A_{i} / \ell_{A_{i}}}},
$$

where $V_{b}$ is the bulk volume of the core, $A_{\mathrm{i}}$ the area open to imbibition, $l_{A_{i}}$ the distance from $A_{i}$ to the centre of the core,

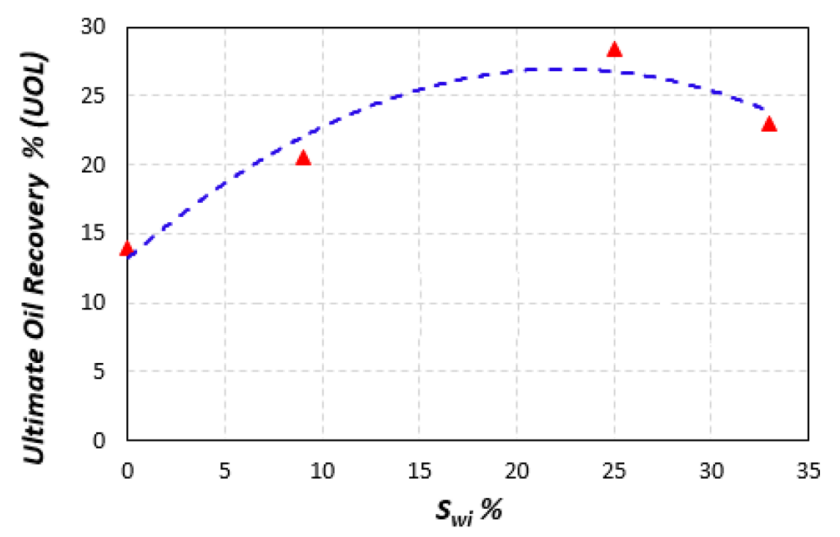

Fig. 3 Ultimate oil recovery versus initial water saturation resulted from imbibition tests on carbonate rocks (test \#1 to 4) and $n$ is the total number of surfaces open to imbibition (Ma et al. 1997).

Figure $2 \mathrm{~b}$ demonstrates that the core with $25 \%$ water saturation gives the highest oil recovery and the core with no water saturation leads to the least oil recovery. The results show that the ultimate oil recovery in test \#4 $\left(S_{\mathrm{wi}}=0.33\right)$ is higher than that in test \#1 $\left(S_{\mathrm{wi}}=0\right)$. These results indicated the positive effect of connate water in the RF of oil in the imbibition test using low-salinity water as imbibing fluid; However, there is no monotonic relationship between ultimate oil recovery and initial water saturation (as presented in Fig. 3). The presence of connate water in the core acts as a conductive layer that provides more efficient interaction between rock surface and imbibition fluid. In the other words, the connate water in the pores bridges between the oil-wet pores and injected brine, such that the ion interaction between brine and oil-wet pore, and thus, the wettability alteration process occurs more efficiently. However, it seems that if the amount of initial water in the porous media is higher than a certain value, then the injected brine more likely flows through the pores occupied by connate water (already water-wet pores). In this case, the oil-wet pores are less likely to be influenced by injected brine and so the wettability alteration of these pores remains unchanged. This difference in the water saturation is shown in Fig. 4, schematically. Figure 4a shows disconnected cluster of water that potentially makes more connection between injected brine and the pores occupied by oil $\left(S_{\mathrm{wi}}\right.$ lower than the mentioned certain value). Figure $4 \mathrm{~b}$ shows the connected path of the connate water distribution that have less interaction with the pore occupied by the oil $\left(\mathrm{S}_{\mathrm{wi}}\right.$ higher than the mentioned certain value).

Figure 5 shows the results of imbibition test performed on the carbonate samples [previously published (McGuire et al. 2005a)] in the absence of initial water with different permeability which shows the impact of permeability on the performance of the low-salinity water injection. The results depict that the imbibition rates (slope of recovery curve) in
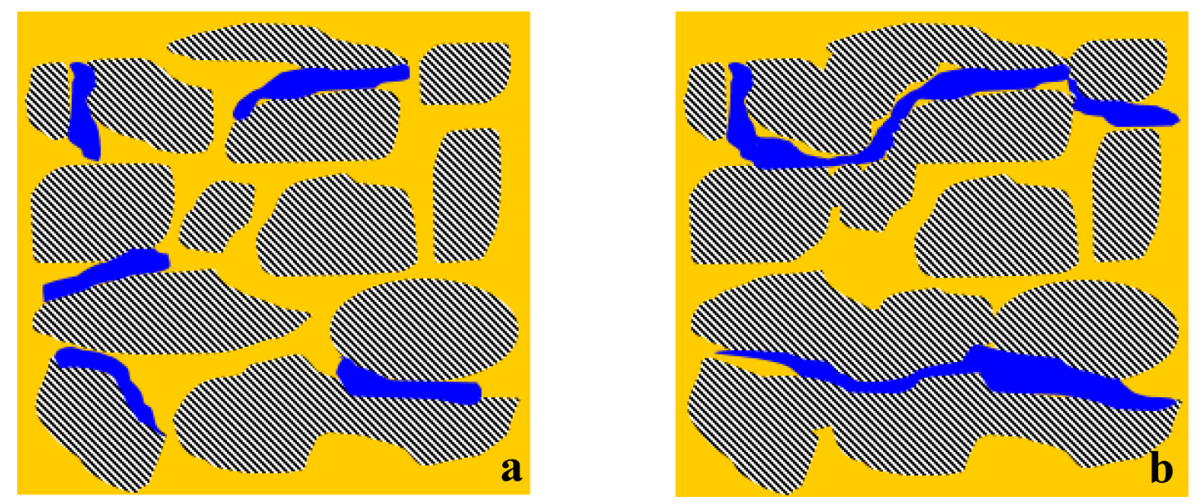

Grain

Connate Water

Oil

Fig. 4 Schematic of two various types of connate water distribution in the rock 
a $\quad$ Res Lim, 10 tdsw, Swi $=0 \% \quad \longrightarrow$ OutCrp Lim, 10 tdsw, Swi= 0\%

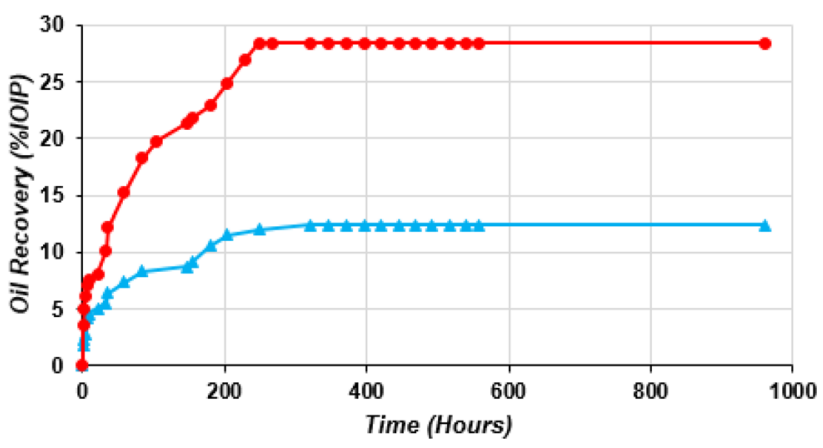

Fig. 5 Oil recovery (\% IOIP) versus time resulted from spontaneous imbibition tests using outcrop carbonate cores $(182 \mathrm{mD})$ and reservoir carbonate $(k=2.46 \mathrm{mD})$ in the absence of connate water satura-

both samples are similar, although the ultimate oil recovery in higher permeable rock is much larger than the reservoir rock (lower permeability). The similar comparison is made between the cores with different permeability but having same initial water saturation $\left(S_{\mathrm{wi}}=25 \%\right)$, as depicted in Fig. 6. As can be seen, the higher permeable rock resulted in lower recovery, as opposed to Fig. 5. In other words, the presence of initial water saturation adversely affected the performance of imbibition test and significantly reduced the oil recovery in higher permeable core. The results depict that the imbibition rate (slope of recovery curve) in the lower permeability rock is larger than that in the higher permeability.

Figure 7 presents the oil recovery of imbibition test for the carbonate and sandstone core with zero initial water saturation. This consequence confirms that the wettability alteration by the low-salinity water takes place in the sandstone faster than that in the carbonate rock. This is attributed to the fact that the presence of the clay in the sandstone rock acts

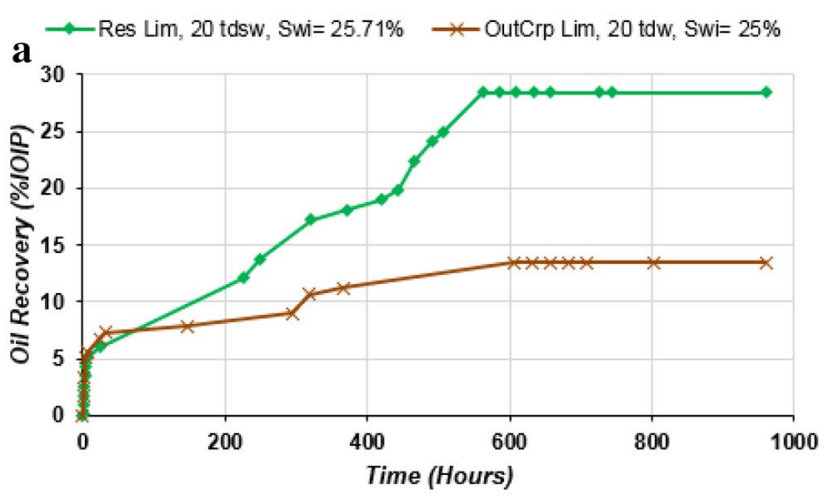

Fig. 6 Oil recovery (\% IOIP) versus time resulted from spontaneous imbibition tests using outcrop carbonate cores $(185 \mathrm{mD})$ and reservoir carbonate $(k=0.4 \mathrm{mD})$ in the presence of connate water satura- b $\quad$ Res Lim, $10 \mathrm{tdsw}, \mathrm{Sw}=0 \% \quad \longrightarrow$ OutCrp Lim, $10 \mathrm{tdsw}, \mathrm{Sw}=0 \%$

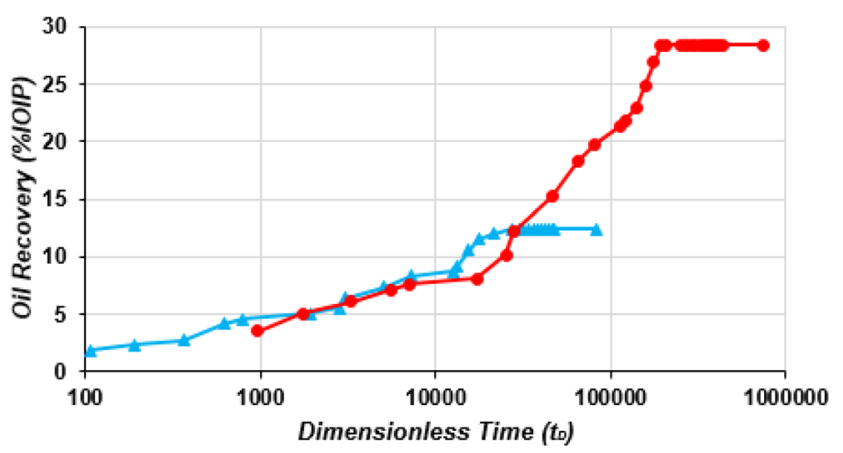

tion $\left(S_{\mathrm{wi}}=0\right)$. Left picture (a) is presented against time and right picture $(\mathbf{b})$ is plotted versus dimensionless time $\left(t_{\mathrm{D}}\right)$ in logarithmic scale (McGuire et al. 2005a)

as a positive factor in wettability alteration by low-salinity water (Austad et al. 2010).

\section{PH analysis and lons tracking}

As already mentioned, one of the important information which can be used to identify the mechanisms involved in the low-salinity injection is the ions and $\mathrm{pH}$ change during experiments. To examine the variation of these parameters in the spontaneous imbibition with diluted sea water, the atomic adsorption analysis and $\mathrm{pH}$ measurement of brine were performed before and after imbibition experiments (Fig. 8). The $\mathrm{pH}$ measurements indicate that the $\mathrm{pH}$ of imbibing fluid (20 tdsw) is slightly increased; however, the change of it is not significant. These data confirm that the oil recovery is not due to increasing of $\mathrm{pH}$ or at least it cannot be the main mechanism in imbibition tests.

The results of cation concentration changes of imbibing fluid are shown in Figs. 9 and 10. Figure 9a depicts the

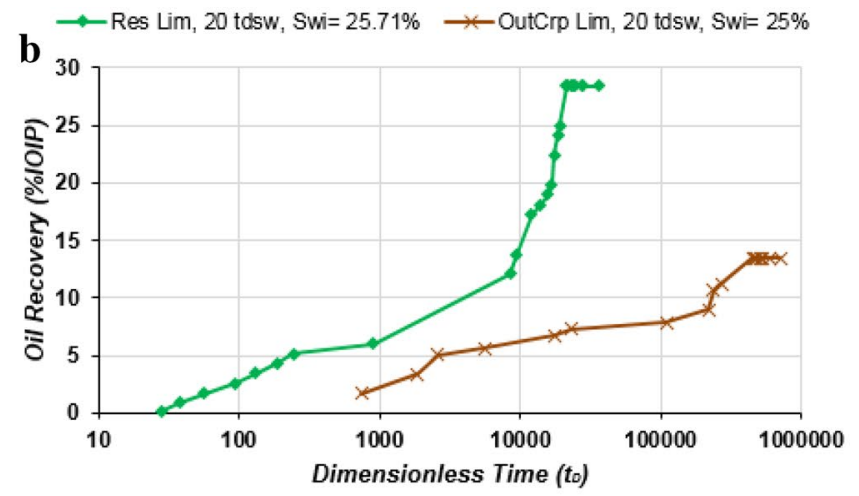

tion $\left(S_{\mathrm{wi}}=25 \%\right)$. Left picture (a) is presented against time and right picture (b) is plotted versus dimensionless time $\left(t_{\mathrm{D}}\right)$ in logarithmic scale 


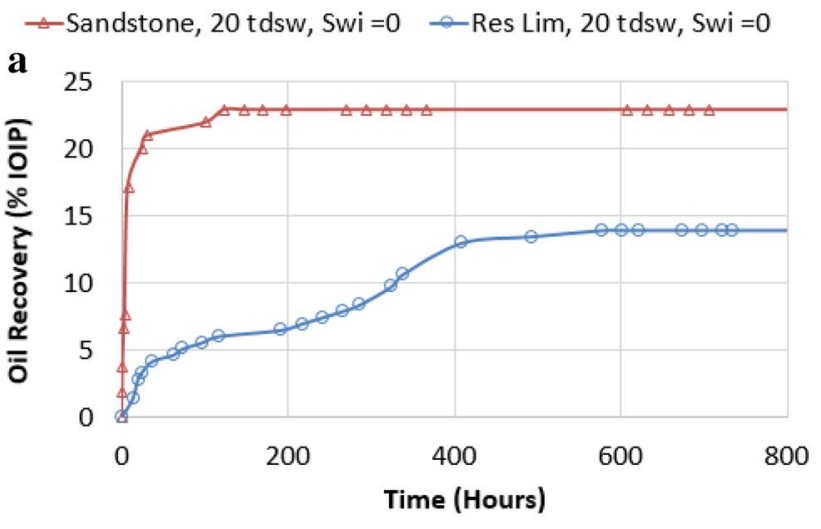

Fig. 7 Oil recovery (\% IOIP) versus time resulted from spontaneous imbibition tests using reservoir carbonate cores [20] and sandstone in absence of connate water saturation. Left picture (a) is presented

percentages of concentration changes of the various cations in the imbibition fluid for tests 1-4. However, due to the direct contact between imbibing fluid (20-tdsw) and connate water (sea water) during imbibition experiments, the cations can transfer between these two fluids. Therefore, to obtain more accurate information about the ion adsorption-desorption between fluid and rock surface, the final ion concentration results are compared against the equilibrium cation concentration of imbibition and connate water. The equilibrium cation concentration is obtained by material balance of the mixed connate water and imbibing brine. The obtained value is observed in Fig. 9b. As can be observed from this figure, the concentration of sodium $\left(\mathrm{Na}^{+}\right)$and calcium $\left(\mathrm{Ca}^{2+}\right)$ has been decreased, almost in the all of experiments (1-4), whereas, except test \#1, the amounts of potassium $\left(\mathrm{K}^{+}\right)$remain constant and the concentrations of magnesium $\left(\mathrm{Mg}^{2+}\right)$ increase in all the tests. In the case of test \#1, due to the absence of connate water, there is not any equilibrium state between ions in brine and rock surface before experiment, so that the cations are adsorbed in the rock surface. According to the suggested mechanism for connate water role in wettability alteration (Fig. 4), there is no bridge of brine in this experiment which, in turn, leads to low contact area between rock surface and imbibing fluid for wettability alteration, and consequently, the recovery factor is lower than tests \#2-4. In addition, the ion analyses demonstrate the adsorption of sodium $\left(\mathrm{Na}^{+}\right)$and calcium $\left(\mathrm{Ca}^{2+}\right)$ on the rock surface, while the magnesium $\left(\mathrm{Mg}^{2+}\right)$ from the rock is released to the brine for experiments 2 to 4 . The comparison of divalent cation concentrations shows that either minimum adsorption of $\left(\mathrm{Ca}^{2+}\right)$ and maximum desorption of magnesium $\left(\mathrm{Mg}^{2+}\right)$ lead to maximum oil recovery of spontaneous imbibition (except test \#1 which no initial water presents in the core).

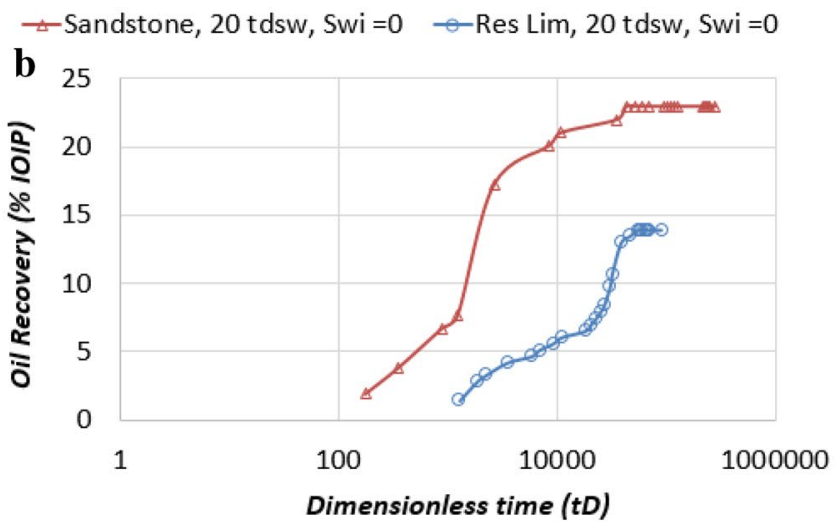

against time and right picture (b) is plotted versus dimensionless time $\left(t_{\mathrm{D}}\right)$ in logarithmic scale

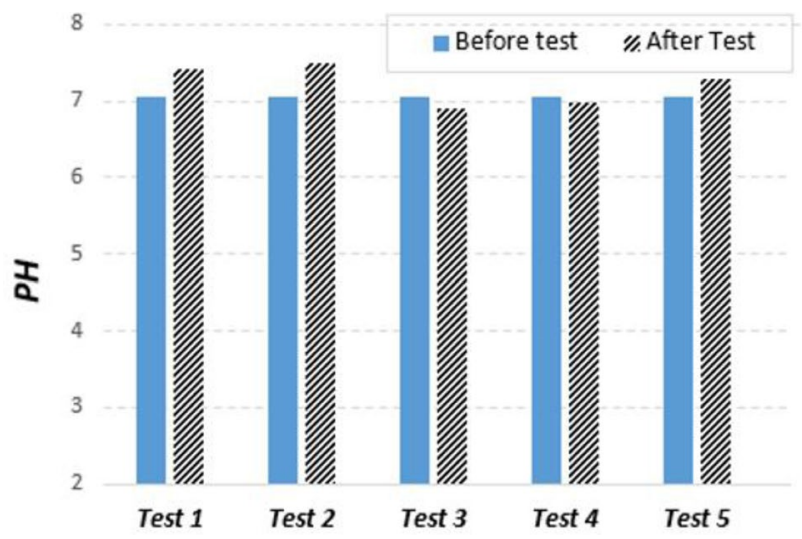

Fig. $8 \mathrm{pH}$ of brine at the beginning and end of spontaneous imbibition test

To investigate the impact of permeability on the ion analysis during low-salinity imbibition with diluted sea water, the ion concentration changes for test 3 (low permeable core with $S_{\mathrm{wc}}=0.25$ ) and test 5 (high permeable core with $S_{\mathrm{wc}}=0.25$ ) are measured and compared in Fig. 10. According to Table 5, the $S_{\mathrm{wc}}$ is identical in test 3 and 5. The cation concentration measurement indicates that the ion-exchange pattern is the same for outcrop and reservoir carbonates with identical lithology and $S_{\mathrm{wc}}$; however, the concentration changes have higher amounts in the case of high permeable core plug which could be due to more contact between rock surface and imbibed fluid in high permeable core. Therefore, it can be concluded that, among the studied cations, the concentration change of $\mathrm{K}^{+}$is ignorable; however, the amounts of $\mathrm{Na}^{+}$and $\mathrm{Ca}^{2+}$ reduced in the imbibing fluid and $\mathrm{Mg}^{2+}$ released to the fluid which confirm that these three cations are active for wettability alteration of carbonate rocks in the

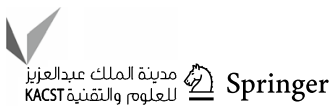




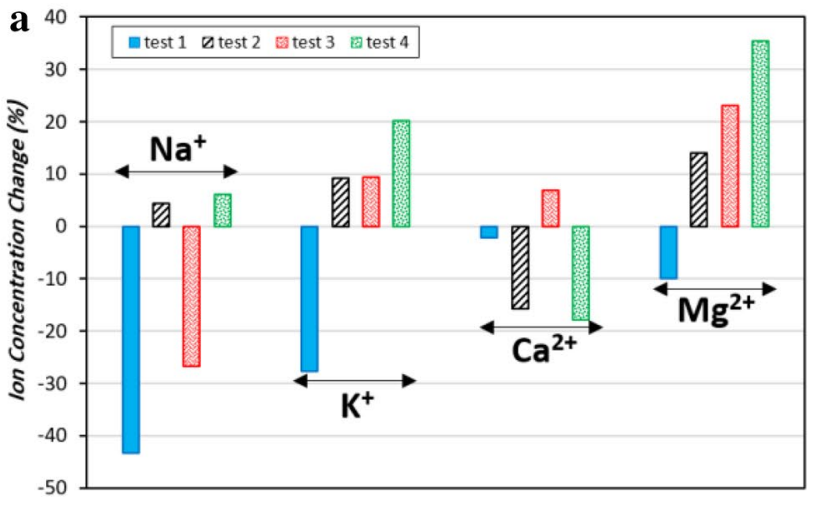

Fig. 9 Percentage of ion concentration change for test 1-4. Left picture (a) is the percentage of ion concentration change and right picture (b) shows the percentage of ion concentration change in com-

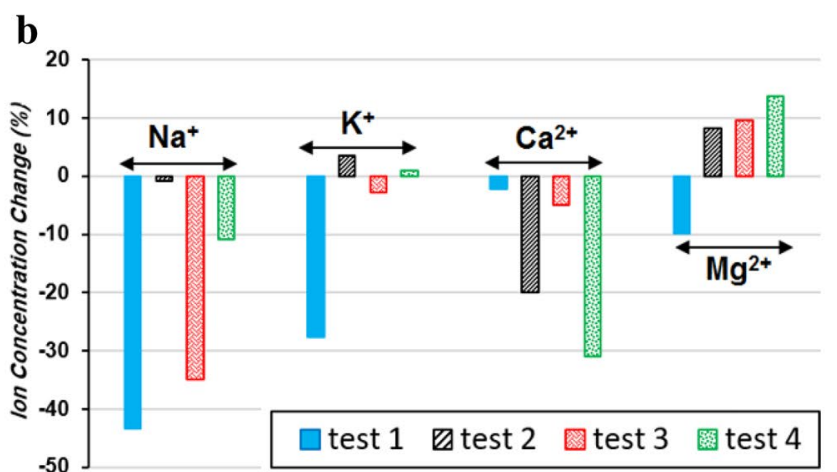

parison with the final concentration of ions when the initial water and imbibing fluid are mixed

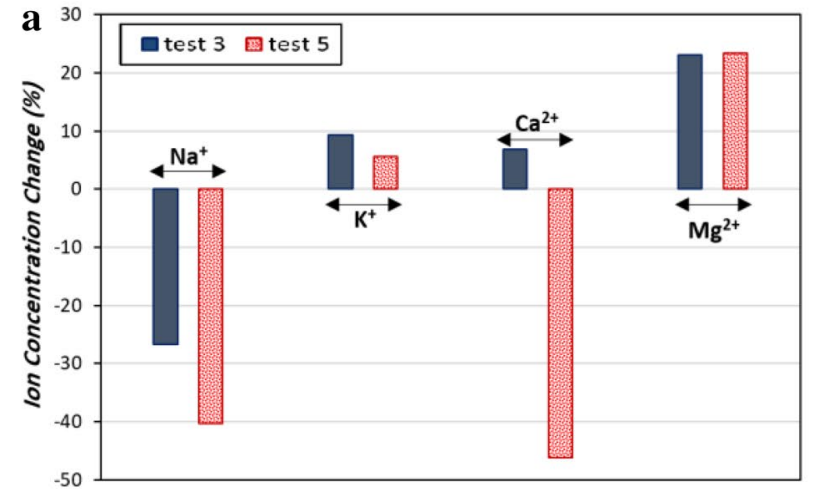

Fig. 10 Percentage of ion concentration change for test 3 (low permeable reservoir carbonate rock, $S_{\mathrm{wc}}=0.25, k=0.4 \mathrm{mD}$ ) and test 5 (high permeable outcrop carbonate rock, $\left.S_{\mathrm{wc}}=0.25, k=185 \mathrm{mD}\right)$. Left picture (a) depicts the percentage of ion concentration change and right

presence of sea water as initial water and diluted sea water as imbibing fluid.

\section{Conclusions}

The main conclusions drawn from this study are given below:

1. The presence of initial water saturation in the reservoir rock may have positive and negative effect of the wettability alteration in the low-salinity water injection. Increasing the initial water to a certain value positively influences the oil recovery whereas, after that, its impact is negative. Based on the mechanism explained in this paper, the optimum value of initial water saturation depends on and fluid distribution and rock type and pore geometry. This conclusion is an alert for the

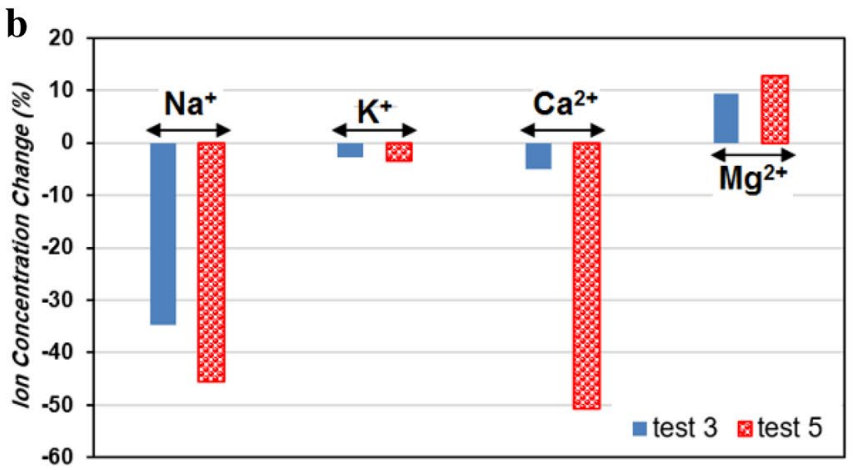

picture (b) shows the percentage of ion concentration change in comparison with the final concentration of ions when the initial water and imbibing fluid are mixed

reservoirs with the initial water which are candidate for low-salinity injection (e.g., the reservoirs were already under secondary water flooding).

2. The results of rocks with different permeability depicted that the conductivity of rock (permeability) can unfavorably affect the oil recovery when the water presents in the rock. Although, generally, the increasing of permeability increases the oil recovery, the presence of water in the reservoir can diminish this effect.

3. The $\mathrm{pH}$ measurements indicated that the $\mathrm{pH}$ of imbibing fluid is slightly changed, and thus, the oil recovery is not due to increasing of $\mathrm{pH}$ and it cannot be the main mechanism in wettability alteration.

4. The ion analyses demonstrated the adsorption of sodium $\left(\mathrm{Na}^{+}\right)$and calcium $\left(\mathrm{Ca}^{2+}\right)$ on the rock surface, while the magnesium $\left(\mathrm{Mg}^{2+}\right)$ from the rock is released to the brine. The comparison of divalent cation concentrations shows that the minimum adsorption of $\left(\mathrm{Ca}^{2+}\right)$ and maxi- 
mum desorption of magnesium $\left(\mathrm{Mg}^{2+}\right)$ lead to maximum oil recovery of spontaneous imbibition. The results confirm that these three cations are active for wettability alteration of carbonate rocks in the presence of sea water as initial water and diluted sea as imbibing fluid.

\begin{abstract}
Acknowledgements The authors acknowledge the National Iranian South Oil Company (NISOC), for generously funding the project as well as granting the permission to publish this paper.
\end{abstract}

Open Access This article is distributed under the terms of the Creative Commons Attribution 4.0 International License (http://creativeco mmons.org/licenses/by/4.0/), which permits unrestricted use, distribution, and reproduction in any medium, provided you give appropriate credit to the original author(s) and the source, provide a link to the Creative Commons license, and indicate if changes were made.

\section{References}

Alagic E, Skauge A (2010) Combined low salinity brine injection and surfactant flooding in mixed-wet sandstone cores. Energy fuels 24(6):3551-3559

Al-Attar HH (2010) Experimental study of spontaneous capillary imbibition in selected carbonate core samples. J Petrol Sci Eng 70(3):320-326

Al-Attar HH, Mahmoud MY, Zekri AY, Almehaideb R, Ghannam M (2013) Low-salinity flooding in a selected carbonate reservoir: experimental approach. J Pet Explor Prod Technol 3(2):139-149

Amyx JW, Bass JR, Daniel M, Whiting RL (1988) Petroleum reservoir engineering: physical properties. McGraw-Hill, Inc, USA

Anderson WG (1986) Wettability literature survey-part 2: wettability measurement. J Pet Technol 1246-1262

Austad T, RezaeiDoust A, Puntervold T (2010) Chemical mechanism of low salinity water flooding in sandstone reservoirs. SPE improved oil recovery symposium, Tulsa, Oklahoma, USA

Austad T, Shariatpanahi SF, Strand S, Black CJJ, Webb KJ (2011) Conditions for a low-salinity enhanced oil recovery (EOR) effect in carbonate oil reservoirs. Energy Fuels 26(1):569-575

Gandomkar A, Rahimpour MR (2015) Investigation of low-salinity waterflooding in secondary and tertiary enhanced oil recovery in limestone reservoirs. Energy Fuels 29(12):7781-7792. https://doi. org/10.1021/acs.energyfuels.5b01236

Green DW, Willhite GP (1998a) Enhanced oil recovery, vol 6. Henry L. Doherty Memorial Fund of AIME, Society of Petroleum Engineers Richardson, TX

Green DW, Willhite GP (1998b) Enhanced oil recovery. vol 8. Society of Petroleum Engineers Inc., USA

Hadia NJ, Hansen T, Tweheyo MT, Torsæter O (2012) Influence of crude oil components on recovery by high and low salinity waterflooding. Energy Fuels 26(7):4328-4335

Hendraningrat L, Li S, Torsæter O (2013) Enhancing oil recovery of low-permeability berea sandstone through optimised nanofluids concentration. The SPE Enhanced Oil Recovery, Kuala Lumpur, Malaysia, 2013/7/2

Hognesen E, Jens S, Strand, Austad T (2005) Waterflooding of preferential oil-wet carbonates: oil recovery related to reservoir temperature and brine composition. SPE Europec/EAGE Annual Conference, Madrid, Spain, 2005/1/1

Karimi A, Fakhroueian Z, Bahramian A, Khiabani NP, Darabad JB, Azin R, Arya S (2012) Wettability alteration in carbonates using zirconium oxide nanofluids: EOR implications. Energy Fuels 26 (2):1028-1036

Lager A, Webb KJ, Black CJJ, Singleton M, Sorbie KS (2008) Low salinity oil recovery - an experimental investigation. Petrophysics $49(01)$

Ligthelm D, Jacob J, Gronsveld J, Hofman N, Brussee F, Marcelis, van der H, Linde (2009) Novel waterflooding strategy by manipulation of injection brine composition. In: The 2009 SPE EUROPEC/EAGE Annual Conference and Exhibition, Amsterdam, The Netherlands, 2009/1/1

Ma S, Morrow NR, Zhang X (1997) Generalized scaling of spontaneous imbibition data for strongly water-wet systems. Pet Sci Eng 18:165-178

Mahani H, Berg S, Ilic D, Bartels W-B, Joekar-Niasar V (2015a) Kinetics of low-salinity-flooding effect. In: The SPE Enhanced Oil Recovery, Kuala Lumpur, Malaysia, 2015/2/1

Mahani H, Keya AL, Berg S, Bartels W-B, Nasralla R, Rossen WR (2015b) Insights into the mechanism of wettability alteration by low-salinity flooding (LSF) in carbonates. Energy Fuels 29(3):1352-1367

McGuire PL, Chatham JR, Paskvan FK, Sommer DM, Carini FH (2005a) Low salinity oil recovery. An Exciting New EOR Opportunity for Alaska's North Slope. SPE Western Regional Meeting, Irvine, California, 2005/1/1

McGuire PL, Chatham JR, Paskvan FK, Sommer DM, Carini FH (2005b) Low salinity oil recovery: an exciting new EOR opportunity for Alaska's north slope. In: The 2005 SPE Western Regional Meeting, Irvine, CA, USA, 2005/1/1

Morrow NR, Mason G (2001) Recovery of oil by spontaneous imbibition. Curr Opin Colloid Interface Sci 6(4):321-337. https:// doi.org/10.1016/S1359-0294(01)00100-5

Morrow NR, Tang GQ, Valat M, Xie X (1998) Prospects of improved oil recovery related to wettability and brine composition. J Pet Sci Eng 20(3-4):267-276

Nasralla RA, Mohammed B, Alotaibi, Nasr-El-Din HA (2011) Efficiency of oil recovery by low salinity water flooding in sandstone reservoirs. SPE Western North American Region Meeting, Anchorage

Needham RB, Doe PH (1987) Polymer flooding review. J Petrol Technol 39(12):1503-1507. https://doi.org/10.2118/17140-PA

Puntervold T, Strand S, Austad T (2007) New method to prepare outcrop chalk cores for wettability and oil recovery studies at low initial water saturation. Energy Fuels 21(6):3425-3430

Rashid S, Mousapour MS, Ayatollahi S, Vossoughi M, Beigy AH (2015) Wettability alteration in carbonates during "Smart Waterflood": underlying mechanisms and the effect of individual ions. Colloids Surf A 487:142-153

RezaeiDoust A, Puntervold T, Strand S, Austad T (2009) Smart water as wettability modifier in carbonate and sandstone: a discussion of similarities/differences in the chemical mechanisms. Energy fuels 23(9):4479-4485

Rivet S, Lake LW, Pope GA (2010) A Coreflood Investigation of Low-Salinity Enhanced Oil Recovery. In: SPE annual technical conference and exhibition, Florence, Italy, 2010/1/1

Romanuka J, Hofman J, Ligthelm DJ, Suijkerbuijk B, Marcelis F, Oedai S, Brussee N, van der Linde H, Aksulu H, Austad T (2012) Low salinity EOR in carbonates. In: SPE Improved Oil Recovery Symposium, Tulsa, Oklahoma, USA, 2012/1/1

Salathiel RA (1973) Oil recovery by surface film drainage in mixedwettability rocks. J Pet Technol 25(10):1216-1224

Samira M, Hamidreza S, Esfahany MN (2018) Impact of salinity and connate water on low salinity water injection in secondary and tertiary stages for enhanced oil recovery in carbonate oil reservoirs. J Geophys Eng 15(4):1242 
Schembre JM, Tang G-Q, Kovscek AR (2006) Wettability alteration and oil recovery by water imbibition at elevated temperatures. J Petrol Sci Eng 52(1):131-148

Shaddel S, Tabatabae-Nejad SA (2015) Alkali/surfactant improved low-salinity waterflooding. Transp Porous Media 106(3):621-642

Shaddel S, Hemmati M, Zamanian E, Moharrami N (2014) Core flood studies to evaluate efficiency of oil recovery by low salinity water flooding as a secondary recovery process. J Pet Sci Technol 4(1):47-56

Shaker Shiran B, Skauge A (2012) Wettability and oil recovery by low salinity injection. In: SPE EOR conference at oil and gas West Asia, Muscat, Oman, 2012/1/1

Shaker Shiran B, Skauge A (2013) Enhanced oil recovery (EOR) by combined low salinity water/polymer flooding. Energy Fuels 27(3):1223-1235

Shehata AM, Hisham A, Nasr El-Din (2015) Spontaneous imbibition study: effect of connate water composition on low-salinity waterflooding in sandstone reservoirs. In: SPE Western Regional Meeting, Garden Grove, California, USA, 2015/4/27

Tang GQ, Morrow NR (1997a) Salinity, temperature, oil composition, and oil recovery by waterflooding. SPE Reserv Eng 12(04):269-276

Tang G-Q, Morrow NR (1999) Influence of brine composition and fines migration on crude oil/brine/rock interactions and oil recovery. $\mathrm{J}$ Petrol Sci Eng 24(2):99-111

Tang GQ, Norman RM (1997b) Salinity, temperature, oil composition, and oil recovery by waterflooding. SPE Reservoir Eng 12(04):269-276

Tiab D, Donaldson EC (2004) Petrophysics: theory and practice of measuring reservoir rock and fluid transport properties. Gulf Professional Publishing, USA

Viksund BG, Morrow NR, Ma S, Wang W, Graue A (1998) Initial water saturation and oil recovery from chalk and sandstone by spontaneous imbibition. In: International Symposium of Society of Core Analysts, The Hague

Wickramathilaka S, Howard JJ, Morrow NR, Buckley J (2011) An experimental study of low salinity water flooding and spontaneous imbibition. In: 16th European symposium on improved oil recovery, Cambridge, UK

Zaeri M, Reza R, Hashemi H, Shahverdi, Sadeghi M (2018) Enhanced oil recovery by low salinity water for carbonate reservoirs using spontaneous imbibition oil recovery. Pet Sci

Zahid A, Shapiro AA, Skauge A (2012) Experimental studies of low salinity water flooding in carbonate reservoirs: a new promising approach. In: SPE EOR Conference at Oil and Gas West Asia, Muscat, Oman

Zhang P, Austad T(2006) Wettability and oil recovery from carbonates: effects of temperature and potential determining ions. Colloids Surf A 279(1):179-187

Zhang Y, Morrow NR (2006) Comparison of secondary and tertiary recovery with change in injection brine composition for crude-oil/ sandstone combinations. In: The $2006 \mathrm{SPE} / \mathrm{DOE}$ symposium on improved oil recovery, Tulsa, Oklahoma, USA, 2006/1/1

Zhang P, Tweheyo MT, Austad T(2007) Wettability alteration and improved oil recovery by spontaneous imbibition of seawater into chalk: impact of the potential determining ions $\mathrm{Ca}^{2+}, \mathrm{Mg}^{2+}$, and $\mathrm{SO}_{4}{ }^{2-}$. Colloids Surf A 301(1):199-208

Zhou X, Morrow NR, Ma S (2000) Interrelationship of wettability, initial water saturation, aging time, and oil recovery by spontaneous imbibition and waterflooding. SPE J 5(02):199-207

Publisher's Note Springer Nature remains neutral with regard to jurisdictional claims in published maps and institutional affiliations. 